\title{
Violência doméstica, infância e rede de apoio*1
}

\section{Domestic violence, chilhood and support network}

Leila Maria Amaral Ribeiro*2

Ligia Maria Costa Leite*3

Promove discussão teórica sobre o desempenho das redes de apoio no caso da violência doméstica na infância, os sentidos da violência e as formas de enfrentamento da questão. Retrata a rede de apoio e a infância nas políticas públicas. Discute a precariedade das redes na abordagem da violência doméstica. Propõe modificações na mentalidade da gestão pública e na formação de recursos humanos na área.

Palavras-chave: Infância, rede de apoio, violência doméstica, formação de recursos

*1 Este artigo faz parte da linha de pesquisa Violência Doméstica e Psicanálise (VIDPSI) vinculada ao Núcleo de Assistência Integrada ao Ensino e a Pesquisa (NAIPE) do Serviço de Psiquiatria da Infância e Adolescência (SPIA) do IPUB/UFRJ e da produção da autora para o pós-doutorado realizado no Programa de Pós-graduação em Psiquiatria e Saúde Mental do IPUB/UFRJ. (Rio de Janeiro, RJ, Brasil).

*2 Universidade Federal do Rio de Janeiro - UFRJ (Rio de Janeiro, RJ, Brasil).

*3 Universidade Federal do Rio de Janeiro - UFRJ (Rio de Janeiro, RJ, Brasil). 


\section{Violência doméstica: cenário e enfrentamento no Brasil}

No Brasil as pesquisas sobre a violência que envolve crianças e adultos no ambiente doméstico ainda são precárias e dificultam falar da situação com a clareza necessária para produzir intervenções que ultrapassem a punição e a repressão. A complexidade desse fenômeno, aliada à demanda surgida em um serviço de saúde mental para a infância e adolescência de um hospital universitário público de referência, resultou em um programa voltado à violência doméstica com atividades de psicoterapia, prevenção, informação e treinamento de multiplicadores, além de pesquisas sobre o tema. As ações do programa podem contribuir tanto para o melhor entendimento da inter-relação dos diversos aspectos da violência que envolve as crianças e os seus familiares, quanto para explorar a atuação das redes de apoio em suas diversas formas de apresentação, seja família, escola, atenção básica e outras.

Analisar a violência doméstica que envolve adultos e crianças significa descortinar seu contexto e época a fim de que apareçam os elementos em jogo em cada situação. Conforme Gonçalves (1999), "ao se compreender cada ato na cultura que o sustenta e o produz, vê-se que o fenômeno da violência torna-se mais complexo, e fica demonstrada a ineficácia em tentar fazê-lo linear" (apud Brito, 1999, p. 137). Para ela, atos em culturas distintas não compartilham o mesmo sentido. Diz ainda que a cultura que estimula e mantém a violência é a mesma que a desencoraja e pune.

Os primeiros estudos e publicações sobre a violência doméstica na América Latina datam da década de 1970. No Brasil, os primeiros estudos apareceram em 1973 na Faculdade de Ciências Médicas da Santa Casa de São Paulo, e, em 1975, no Hospital Jesus no Rio de Janeiro. Nos anos 1980 a sociedade civil brasileira 
articulou-se com o poder público para propor ações de identificação e enfrentamento das situações de violência a que crianças e adolescentes estavam expostos. Os reflexos dessa articulação são testemunhados ao longo dos anos 1990 e tornam-se marco importante no Brasil do século XX para encarar a violência nas diversas formas em que se apresenta. Os maus-tratos contra a criança e o adolescente receberam especial destaque nesse período com a promulgação da Lei 8069/90, Estatuto da Criança e do Adolescente - ECA, que desencadeou mudanças no convívio social com a infância e a adolescência no país. As noções introduzidas pelo ECA — crianças e adolescentes detentores de direitos e merecedores de proteção integral - causaram impacto na sociedade comparável, talvez, ao ocorrido na educação infantil, com o surgimento da noção da inocência, no século XVII, que exigiu a reconfiguração da sociedade para se adaptar às novas concepções. Essa reorganização envolveu a promoção de redes de apoio e proteção voltadas à infância e adolescência.

Em relação ao Brasil, pode-se dizer que, "a dimensão da violência familiar ainda não pôde ser adequadamente identificada. No entanto, a despeito do conhecimento ainda ser incipiente, algumas pesquisas sobre o tema têm apontado para um cenário que merece ser enfrentado imediatamente" (Reichenheim, 2000, p. 611). A partir da constatação de que o conhecimento sobre a questão é inicial e sua abordagem é diversa, de acordo com a localidade, o tema mobiliza equipes para criação de propostas específicas para o combate, prevenção e tratamento do problema. Possibilita-se, assim, investigações que expõem uma realidade e "com isso, cresce também a necessidade de aprofundar e aprimorar instrumentos voltados para a detecção e o acompanhamento de vítimas e de suas famílias, bem como de um instrumental de aferição para ser aplicado em contextos de pesquisa" (p. 611). Para Reichenheim et al. (2000), a instalação e a expansão de programas de investigação, que visam a construção de instrumentos de coleta de informação é mais complexa no Brasil. Dizem eles que, majoritariamente, os instrumentos utilizados nas pesquisas não são produzidos para a realidade brasileira.

Alguns sentidos da violência

Conceitualmente, a violência é apresentada como ação com força ou grande impulso; ímpeto, impetuosidade. O termo violentar caracteriza exercer violência contra, coagir, constranger, obrigar, forçar, arrombar. O violento (Caldas Aulete, 2018, digital) pode ser lido como o que atua com força ou 
também como impetuoso, arrebatado, fogoso, intenso e veemente. O termo pode ainda ser definido como característica de violento, ato violento ou ato de violentar; constrangimento físico ou moral; uso da força; coação (Dicionário Aurélio, 2018). Violência tem origem no latim violentia que carrega o significado de "caráter violento ou bravio, força. $\mathrm{O}$ verbo violare significa tratar com violência, profanar, transgredir" (Michaud, 1989). Para Michaud, esses termos, por sua vez, devem ser referidos a vis, que quer dizer força, vigor, potência, violência, emprego de força física, mas também quantidade, abundância, essência ou caráter essencial de uma coisa. Considera-a como meio de domínio, de subjugação, de correlação de forças e instrumento fundamental para que outros setores se oponham às diretrizes e situações determinadas.

Do ponto de vista legal, manifesta-se o aspecto criminal e da violação da lei que estaria presente na violência. Segundo essa perspectiva, nem todo fato violento é criminal e nem todo ato criminal é violento; a violência é considerada resultante da vontade individual, o que permite aos legisladores atribuir responsabilidades na execução do ato violento, além de centrar o interesse no agressor e na vítima. Isola-se, assim, o ato violento do contexto social onde é gerado.

Sob o ponto de vista filosófico, para Minayo (2005), um dos mais vigorosos pensamentos sobre a violência é o de Hannah Arendt que, apesar de considerá-la um instrumento para a conquista do poder, não a confunde com ele. Diz ainda que, para Arendt, a violência decorre da incapacidade de argumentação e não vê positividade nela. Essa posição é expressa de forma contundente ao evidenciar as formas de crueldade das experiências políticas totalitárias do nazismo e fascismo. Para ela, ainda, Arendt "reage aos autores que promovem uma visão teleológica da violência" (p. 16).

Outro ponto de vista a ser destacado é o da saúde pública, segundo o qual a violência é considerada problema ao ter consequências físicas, como incapacidade, sequelas, perda de potencial e qualidade de vida. Os estudos nessa área são centrados na frequência e gravidade das lesões produzidas, na delimitação de grupos de risco e no impacto que têm as lesões nos serviços de saúde. Para Minayo (2006), o caso da violência "é exemplar para entendermos a transição que junta questões sociais e problemas de saúde. Violência não é um problema médico típico, é, fundamentalmente, um problema social que acompanha toda a história e as transformações da humanidade" (p. 22).

Apesar de tema recorrente, era pouco abordada pela área da saúde pública até 2002 (Minayo, 2006, p. 22), quando no Relatório Mundial sobre Violência e Saúde a Organização Mundial da Saúde - OMS definiu o 
problema como "uso intencional da força física ou do poder real ou em ameaça, contra si próprio, contra outra pessoa, ou contra um grupo ou uma comunidade, que resulte ou tenha qualquer possibilidade de resultar em lesão, morte, dano psicológico, deficiência de desenvolvimento ou privação" (Krug et al., 2002, p. 5). Minayo (2005) destaca, também, diferentes momentos do pensamento freudiano no qual a temática é abordada até chegar à ideia de construção de identidade de interesses da qual surgem vínculos emocionais e a preferência pela civilização, o diálogo e a convivência pacífica, em detrimento da imposição pela força física. Desse modo, "os conflitos de interesse nas sociedades modernas, a partir de então, passam a ser mediados pelo direito e pela lei; e a comunidade de interesses, pela identidade e pela busca do bem coletivo" (p. 16).

Destaca-se, ainda, a proposição de Leite (2010) de uma violência silenciosa, que perpassaria todas as demais e "atinge a grande maioria do nosso povo e sua luta cotidiana pela sobrevivência imediata" (p. 101). Para ela, é uma forma "sutilmente escamoteada, camuflada e, talvez, muito mais violenta do que a sua forma aparente, expressa pela tortura ou pela perseguição policial: a violência da falta de direitos básicos, como o trabalho, a educação, a saúde, a justiça, entre outros" (p. 101). Ao aprofundar o escopo dessa forma de expressão da violência, Leite (2010) a considera uma conduta difusa naturalizada pelos envolvidos ao perpassar todas as outras já estudadas e catalogadas, sejam elas físicas, psíquicas ou simbólicas. Por surgir de modo quase imperceptível, é impossível de ser quantificada por meio de instrumentos específicos, sendo ignorada para estatísticas oficiais.

Considerada por alguns problema de grupos sociais específicos, e por outros como afetação eminentemente individual, a violência mostra sua complexidade. Logo, sua análise requer instrumental que possibilite clarear cada vez mais o entendimento das situações que envolvem crianças e adultos e que seja capaz de sustentar um diálogo entre o indivíduo e a cultura na qual está inserida. Há que se considerar que muitos elementos estão arrolados nas situações de violência e que estar envolvido em algo significa fazer parte do processo, estar contido em seus limites.

\section{Redes de apoio como politica pública}

A compreensão da família como grupo com identidade própria, um microcosmo ou uma forma de agregação social inerente ao humano, 


\section{SAÚDE MENTAL}

possibilita pensá-la como rede de apoio para seus membros. Essa seria a primeira estrutura que a criança tem à sua disposição e dela depende para o processo evolutivo. Uma rede pode ser caracterizada por suas linhas e pontos, sendo as primeiras consideradas mais importantes que seus pontos, por fazerem as conexões. Segundo Souza (2017),

[...] cada conexão representa sempre um par de pontos, pois uma ligação só pode se estabelecer na medida da existência de dois elementos a serem ligados. Nesse sentido, uma linha vale por dois pontos. Em compensação, cada ponto pode manter uma infinidade de linhas que se projetam dele; pode possuir tantas linhas quantos forem os demais pontos pertencentes à rede a que ele estiver ligado.

Em relação a organização social, Oliveira et al. (2006), definem a rede como "um padrão organizacional que prima pela descentralização na tomada de decisão e pela democracia, pela flexibilidade e pelo dinamismo de sua estrutura, pelo alto grau de autonomia de seus membros e pela horizontalidade das relações entre os seus elementos" (p. 144). Para eles, a rede atua pela radical desconcentração de poder. A implantação de redes de proteção e apoio, segundo Oliveira et al. (2006), muitas vezes, não implica grandes investimentos, seja por parte do setor público, seja do privado. Sua implantação tem como base a mudança na forma de o profissional orientar, acompanhar, diagnosticar e prestar assistência às vítimas de situação de risco para violência com o apoio dos meios de proteção legal. Inicialmente, não se faz necessária a criação de novos serviços, "mas sim a integração dos existentes, necessitando de pessoas sensibilizadas e envolvidas" (p. 144-145).

Algumas premissas dessa forma de trabalho foram destacadas por Deslandes (2006) a partir dos apontamentos feitos por autores como Ube (2002), Bronfman (2000) e Nogueira (1995). Segundo ela, as premissas do trabalho em rede envolvem os aspectos a seguir:

1) negociação para tomada de decisões, respeitando-se a identidade, a autonomia e a vocação de cada participante; 2) criação de espaços de conversação e expressão coletiva; 3) consciência de que a atuação deve ser constantemente reavaliada para se ajustarem seus rumos; 4) relações de poder horizontais e democráticas. A análise das redes deve ainda levar em conta sua historicidade e o contexto sociopolítico em que se inserem. (Feldman-Bianco, 1987, apud Deslandes, 2006, p. 139-140)

A apresentação feita por Oliveira et al. (2006) possibilita acompanhar o funcionamento do trabalho em rede que procura levar em conta tais premissas. Nela pode-se identificar o modo de articulação dos setores da saúde, educação 
e assistência social, que prestam serviços cruciais de apoio no contexto da violência que envolve adultos e crianças. Segundo Oliveira et al. (2006),

[...] frente a uma situação de violência, à área da saúde cabe a confirmação do diagnóstico e seu tratamento, o encaminhamento aos serviços de saúde mental e o tratamento de fatores potencializadores da violência, como o uso de álcool e outras drogas. $\mathrm{Na}$ área da educação, são indispensáveis o acompanhamento diferenciado da criança ou do adolescente e o apoio pedagógico, minimizando possíveis distúrbios de aprendizagem decorrentes da situação de violência. E, certamente, buscando-se a inclusão dos pais em grupos de orientação e acompanhamento. Os serviços sociais devem ser acionados nos casos em que, dentre os fatores potencializadores da violência, estão a falta de condições dignas de vida e a ausência de suporte familiar. O trabalho integrado tem possibilitado a articulação entre os vários serviços, mobilizando as diferentes equipes para obtenção de melhores resultados. (p. 148)

A integração dos trabalhos de diferentes áreas requer constante adequação da mentalidade dos profissionais. Como dito anteriormente, desde os anos 1980 houve grande mobilização da sociedade civil brasileira, fartamente documentada pela literatura, com proposições de mudanças significativas no modo de abordar as questões da infância e adolescência no Brasil. Esse movimento foi gerador de alterações significativas ao apresentar, dentre outras, a ideia da formação de redes de apoio que produziram mudanças na posição social e política de crianças, adolescentes, e suas famílias que, por sua vez, passaram a demandar trabalhos dessa natureza. Assim, para abordar a violência doméstica,

[...] deve-se constantemente invocar a noção de vinculação: seja psíquica, comunitária, familiar, institucional, seja de causas ou de fenômenos. Uma vinculação dinâmica que favoreça a expansão da vida ou da morte. Que mutuamente afeta e é também afetada e que, absolutamente, não constitui um todo a partir da soma de suas partes, mas, antes de tudo, constrói dinamicamente novas totalidades. (Deslandes, 2006, p. 139)

Dessa diversidade de vínculos psíquicos, comunitários, familiares ou institucionais, decorre uma profusão de vinculações que constituem o cenário no qual a criança está inserida desde o início da vida. Lidar com essa multiplicidade requer abordagens que considerem as especificidades de cada um dos envolvidos na rede quando se trata de situação de violência. Para estabelecer e lidar com esses vínculos que a ela se apresentam, a criança precisará de apoio que lhe propicie condições para produzir seus recursos e desenvolver as estratégias adequadas. 


\section{Violências e as relações com a rede de apoio}

A experiência no trabalho com famílias em situação de violência em um ambulatório público de saúde mental mostra que há recorrência de violências na rede que deveria ser de apoio e proteção às crianças e seus familiares. A repetição da violência pode ser pensada tanto na precariedade dos serviços oferecidos na região de moradia da clientela, como foi apontado por Oliveira (2015), quanto nas dificuldades da rede básica de assistência para identificar situações de violência doméstica na história das crianças encaminhadas para um ambulatório de psiquiatria. Com isso, preceitos do ECA quanto à promoção dos direitos da criança e do adolescente são violados pela reprodução de uma das formas de violência que é a silenciosa, destacada por Leite (2010). Associada a aspectos simbólicos, a forma silenciosa da violência passa a ser aceita como corriqueira, o que a deixa sem condições de ser percebida ou quantificada (Leite, 2010).

Salienta-se também que a produção de dados claros sobre o atendimento de crianças e adolescentes no Brasil contribuiria para um aspecto, apontado por Gonçalves (apud Brito, 1999), relevante na consideração da violência, que é a compreensão de cada ato na cultura "que o sustenta e o produz" (p. 137). Essa compreensão pode se dar tanto pela via do perfil revelado nos registros dos pacientes atendidos, como localização da moradia, sexo, idade, relações familiares, tratamentos realizados, queixa inicial, constituição familiar; quanto na explicitação das dificuldades em identificar as relações familiares como causadoras de sintomas importantes no comportamento, emoções e cognição da criança. Tais dificuldades podem ser superadas com mudanças na forma de assistência às crianças em situação de risco e suas famílias, o que não requer grandes investimentos financeiros, mas novos posicionamentos das equipes, conforme Oliveira et al. (2006).

A consideração da relação entre a externalização de um comportamento da criança e seu contexto familiar pode contribuir para gerar mudanças na forma de atuação da rede de apoio e, por consequência, promover a prevenção e ampliar a atenção às situações de risco. A comparação entre a queixa apresentada pelos responsáveis como deflagradora da busca por um espaço de saúde mental e o esclarecimento dela a partir da avaliação na porta de entrada do serviço especializado, contribuem para entendê-la como um sintoma-índice de outros fatores que levantariam a suspeita de violência doméstica. A queixa, ou sintoma, enunciado a priori pelos responsáveis pode sinalizar que há questões encobertas. Ou seja, as demandas iniciais arroladas como relacionadas ao comportamento da criança podem estabelecer relação inversa com as 
identificadas em uma avalição mais apurada da queixa. Assim, o foco deslocase da criança e amplia-se para o ambiente familiar que pode ser tanto o espaço responsável por acomodar e transmitir a cultura, como proposto por Minuchin (1982), quanto o reprodutor da violência como forma de sustentar as relações, conforme revela a experiência de atendimento.

Ribeiro (2008) afirma que crianças e adultos estão envolvidos nas situações de violência doméstica, cada um a seu modo e de acordo com suas necessidades. Para ela, a partir da demanda - que pode ser por cuidados básicos ou atenção - a criança dirige-se ao adulto com o propósito de ser atendida. $\mathrm{O}$ adulto responderá com seus recursos, que podem ser insuficientes para a criança, que seguirá com suas reivindicações. Nesse cenário, caso o adulto sinta-se impotente ou fragilizado pelas demandas, poderá tentar compensar essa insuficiência com distintos argumentos para encobrir a inadimplência diante da criança. Como recurso encobridor de sua fragilidade, o adulto poderá fazer uso tanto da sua força física ou psicológica, negligenciar nos seus cuidados, abusar sexualmente ou mesmo abandonar a criança no intuito de enfrentar o grande poder que atribui àquela demanda. Nesse cenário, a criança precisará recorrer às estratégias que inventou para sobreviver (Magno, 2017). Tais subterfúgios como desobediência, agitação, hipersexualidade, hiperatividade, dificuldades de aprendizagem, tentativas de suicídio, tristeza, depressão, roubo podem fazer parte das queixas arroladas pelos adultos com os quais ela convive. Assim, o que para a criança é uma estratégia de sobrevivência, para o adulto pode ser um problema apresentado em forma de queixa com foco nela.

Nessa linha de pensamento destaca-se que, para Dolto (1988), há investimentos na relação do adulto com a criança. Pode-se acrescentar que essa vinculação, aparentemente dual, quando presente no grupo familiar, envolve os demais membros desse microcosmo. Acrescenta ainda Dolto (1988), que o ambiente familiar aposta que a criança quer dizer algo. Ela, por sua vez, responderia com o que entende que querem dizer ou provocar-lhe. Logo, haveria um enredamento que pode ser exemplificado pelo não reconhecimento por parte dos outros membros da família de que a situação pode ser prejudicial, danosa e afetar a todos; pela omissão diante do que ocorre com aquela criança específica ou até mesmo ao usufruírem de certo prazer em subjugar alguém. ${ }^{1}$ Configura-se com isso a relação em que os poderes de todos estão

'Discutido por Freud no texto de 1919, "Uma criança é espancada": uma contribuição ao estudo da origem das perversões sexuais. 
em jogo. De um lado, há uma criança, com recursos físicos e psíquicos mais precários que o adulto e que, por isso mesmo, pode envolvê-lo e ser por ele envolvida na situação. Por outro, o adulto, ao sentir-se inadimplente diante da situação que se apresenta, pode reagir de modo que também mostra a demanda insatisfeita.

Pode-se explicitar assim o cenário no qual o comprometimento dos membros da rede familiar se dá pelo convívio e pela conjunção de afetos, como dependências, medos, necessidades e inseguranças do grupo familiar como todo, e que poderão estender-se à rede de apoio extrafamiliar. Vale invocar a importância da consideração da noção dos diferentes vínculos presentes na rede, tal como proposto por Oliveira et al. (2006), sejam eles comunitários, familiares ou institucionais, atrelados à dinâmica que produz novas totalidades. Assim, todos estarão envolvidos na situação de violência e, diante dela, utilizarão seus recursos que, se não adequados, poderão ter efeitos deletérios de sustentação e recrudescimento da violência que pretendem aplacar ou suprimir.

\section{Considerações finais}

Reputa-se que a rede de apoio e proteção, em geral, precisa ser preparada para identificar e notificar as situações de risco entre crianças e familiares. Pode-se dizer que há falta de recursos tanto para professores e equipes pedagógicas das escolas, quanto para os conselheiros tutelares e mesmo aos profissionais da área da saúde para lidarem com a violência doméstica. Um dos indicadores dessa insuficiência é a chegada, a um ambulatório de saúde mental, de questões que envolvem opressões, abusos e constrangimentos decorrentes de precariedades sociais, sem que tenham sido ponderadas. Pode-se dizer que falta suporte às crianças em suas famílias, que, por sua vez, não são devidamente apoiadas nas redes de atenção básica e psicossocial. Tal fato deve-se, algumas vezes, ao despreparo do profissional para a escuta de quem demanda o atendimento básico, a falta de tempo para uma abordagem mais acurada das famílias, escassez de recursos para explorar melhor a queixa apresentada pela família e, ainda, a burocracia envolvida nos encaminhamentos.

Os primeiros passos na abordagem das situações de violência doméstica que envolve adultos e crianças que chegam à atenção básica, por exemplo, são cruciais para seu bom andamento e resolutividade. No entanto, muitas vezes, 
a urgência de diagnóstico e necessidade de encaminhamento podem ser prejudiciais nessa etapa da investigação, tanto por ocasionar endereçamentos equivocados dos casos, ou por atrasar a intervenção que, inicialmente, poderia ser mais eficaz e menos dispendiosa de recursos financeiros e afetivos a serem mobilizados. Paradoxalmente, a demora na intervenção pode contribuir para a cristalização de sintomas e formas de relacionamento familiares que, se identificados e abordados mais cedo, podem ser modificados, gerar menos danos e possibilitar curso melhor para as relações familiares. Tais intervenções passam pela escuta, orientação, identificação de doença física ou mental, inclusão em atividades que possibilitem à família promover o desenvolvimento físico e a integração social da criança.

Diante das fragilidades na abordagem, avaliação e encaminhamento das situações, a rede de apoio disponível não cumpre sua função primordial. Segundo Leite (2010), elas "são precárias, desarticuladas, desestruturadas, atravessadas pela suposta autoridade da rede de defesa de direitos e, como decorrência, nem sempre os direitos e a defesa dos jovens são assegurados. O que se vê é um cenário de relações difíceis e truncadas" (p. 21). A rede que não se comunica entre si não existe de fato.

Sabe-se que nem sempre as medidas mais simples são as mais fáceis de serem adotadas. No entanto, para melhor preparo das gerações futuras, seria importante que as redes de proteção existentes restabelecessem sua função de comunicação e apoio àqueles que atende primariamente. Isso pode começar pela reordenação do fluxo, simplificação dos encaminhamentos, formação continuada das equipes, contato entre os parceiros e outros procedimentos. Todas essas ações são viáveis, têm baixo ou nenhum custo financeiro, requerem, apenas, como apontado por Oliveira et al. (2006), mudança de mentalidade dos produtores e executores de políticas públicas, que contribuiria para desburocratizar os processos e gerar ações mais efetivas e eficazes em áreas que integram as medidas protetivas do ECA,como educação, saúde, lazer e segurança de crianças e seus familiares.

\section{Referências}

Aulete digital (2017). Recuperado em 5 out. 2017 de: <http://www.aulete.com.br/ violento>.

Brito, L. (Org.). (1999). Temas de Psicologia Jurídica. Rio de Janeiro, RJ: Relume-Dumará. 


\section{SAÚDE MENTAL}

Deslandes, S. F. (2006). Redes de proteção social e redes sociais: uma práxis integradora. In C. A. Lima et al. (coord.), Violência faz mal à saúde (Série B. Textos Básicos de Saúde). Brasília, DF: Ministério da Saúde.

Dicionário Aurélio (2017). Recuperado em 5 out. 2017 de: <https:// dicionariodoaurelio.com/violencia>.

Dolto, F. (1988). Dificuldade de viver - psicanálise e prevenção das neuroses. Porto Alegre, RS: Artes Médicas.

Freud, S. (1996). 'Uma criança é espancada': uma contribuição ao estudo da origem das perversões sexuais. In Edição Standard Brasileira das Obras Psicológicas Completas de Sigmund Freud (vol.XVII). Rio de Janeiro: Imago. (Trabalho original publicado em 1919).

Krug, E. G. et al. (2002). World Report on Violence and Health. Geneva: World Health Organization.

Leite, L. (2010). Violência, juventude e saúde mental. Relatório final. Universidade Federal do Rio de Janeiro - UFRJ. Centro de Ciências da Saúde - CCS. Instituto de Psiquiatria - IPUB. Relatório final de pesquisa. Não publicado. Rio de Janeiro.

Magno, M. D. (2017). Só papos 2015. Rio de Janeiro, RJ: Novamente.

Michaud, Y. (1989). A violência. São Paulo, SP: Ática.

Minayo, M. C. S. (2005). Violência: um problema para a saúde dos brasileiros. In Impacto da violência na saúde dos brasileiros. Ministério da Saúde, Secretaria de Vigilância em Saúde. Brasília, DF: Ministério da Saúde.

Minayo, M. C. S. (2006). Conceitos, teorias e tipologias de violência: a violência faz mal à saúde. In Impactos da violência na saúde. Recuperado em 6 fev. 2018, de: <http:// www 1.londrina.pr.gov.br/dados/images/stories/Storage/sec_mulher/capacitacao_ rede\%20/modulo_2/205631-conceitos_teorias_tipologias_violencia.pdf $>$.

Oliveira et al. (2006). Redes de proteção: novo paradigma de atuação - experiência de Curitiba, In C. A. Lima et al. (Coord.). Violência faz mal à saúde. (Série B. Textos Básicos de Saúde). Brasília, DF: Ministério da Saúde.

Oliveira, R. (2015). Programa de porta de entrada do serviço de psiquiatria da infância e adolescência. Monografia do curso de residência IPUB/UFRJ. Rio de Janeiro.

Reichenheim, M. E., Moraes, C L., \& Hasselmannb, M. H. (2000). Equivalência semântica da versão em português do instrumento Abuse Assessment Screen para rastrear a violência contra a mulher grávida. Rev. Saúde Pública, 34(6), 610-16. Recuperado em 6 fev. 2018, de: <www.fsp.usp.br/rsp>.

Ribeiro, L. (2008). A interdependência da criança e do adulto na violência doméstica. In A. Trimboli et al. (Orgs.). Modernidad, tecnologia y aintomas contemporaneos (pp. 181-183). Buenos Aires, Argentina: Associación Argentina de Salud Mental. 
Souza, W. (2017). O que são redes. Recuperado em 15 ago. 2017 de: $<\underline{w w w}$. brasilescola.com/informatica/redes-sem-escalas.htm $>$.

\section{Resumos}

(Domestic violence, childhood and support network)

This paper promotes a theoretical discussion about the performance of support networks in cases of childhood domestic violence, ways of violence, and how to address the issue. It portrays the support network and childhood in public policies. It discusses the deficiency of networks when addressing domestic violence. It proposes changes to the mindset of public administrators and in the formation of human resources in that field.

Key words: Childhood, support network, domestic violence, formation of resources

(Violence domestique,enfance et réseau de soutien)

Il encourage la discussion théorique sur la performance des réseaux de soutien dans le cas de la violence domestique dans l'enfance, les sens de la violence et façons de faire face au problème. Il les décrit dans les politiques publiques et expose la précarité des réseaux dans l'approche de cette violence domestique. Il propose des changements de mentalité de la gestion publique et dans la formation des ressources humaines dans le domaine.

Most clés: Enfance, réseau de soutien, violence domestique, formation de ressources

(Violencia domestica, infancia y red de apoyo)

Promueve una discusión teórica sobre el desempeño de las redes de apoyo en caso de violencia doméstica en la infancia, los sentidos de la violencia y las formas para enfrentar dicha cuestión. Retrata a la red de apoyo y a la infancia en las políticas públicas. Discute la precariedad de las redes en cuanto al abordaje de la violencia doméstica. Propone modificaciones en la mentalidad de la gestión pública y en la formación de recursos humanos en el área.

Palabras clave: Infancia, red de apoyo, violencia doméstica, formación de recursos

(Häusliche Gewalt, Kindheit und Unterstützungsnetzwerk)

Dieser Artikel beschreibt eine theoretische Diskussion über die Leistungen der Unterstützungsnetzwerke bei häuslicher Gewalt in der Kindheit, die Bedeutungen der Gewalt und die Formen der Bekämpfung dieser Problematik. Ferner wird das Netz von Hilfswerken sowie die Kindheit unter dem Blickpunkt öffentlicher Politiken 


\section{SAÚDE MENTAL}

dargestellt. Weiter erörtert der Artikel die prekäre Rolle der Hilfswerke bei der Bekämpfung der häuslichen Gewalt und empfiehlt als Lösung Änderungen in der Mentalität der öffentlichen Verwaltung herbeizuführen sowie in der beruflichen Ausbildung in diesem Bereich.

Schlüsselwörter: Kindheit, Unterstützungsnetzwerk, häusliche Gewalt, Berufliche Ausbildung

Citação/Citation: Ribeiro, L. M. A. (2018, setembro). Violência doméstica, infância e rede de apoio. Revista Latinoamericana de Psicopatologia Fundamental, 21(3), 646-659. http:// dx.doi.org/10.1590/1415-4714.2018v21n3p646.12.

Editores do artigo/Editors: Profa. Dra. Ilka Franco Ferrari

Recebido/Received: 18.6.2018/ 6.18.2018 Aceito/Accepted: 15.7.2018 / 7.15.2018

Copyright: (C) 2009 Associação Universitária de Pesquisa em Psicopatologia Fundamental/ University Association for Research in Fundamental Psychopathology. Este é um artigo de livre acesso, que permite uso irrestrito, distribuição e reprodução em qualquer meio, desde que o autor e a fonte sejam citados / This is an open-access article, which permits unrestricted use, distribution, and reproduction in any medium, provided the original authors and sources are credited.

Financiamento/Funding: As autoras declaram não terem sido financiadas ou apoiadas / The authors have no support or funding to report.

Conflito de interesses/Conflict of interest: As autoras declaram que não há conflito de interesses / The authors have no conflict of interest to declare.

\section{Leila Maria Amaral Ribeiro}

Coordenadora do Programa Violência Doméstica e Psicanálise - Instituto de Psiquiatria da Universidade Federal do Rio de Janeiro - IPUB/UFRJ (Rio de Janeiro, RJ, Br).

leila.ribeiro@ipub.ufrj.br

\section{Ligia Maria Costa Leite}

Professora do Instituto de Psiquiatria da Universidade Federal do Rio de Janeiro - IPUB/

UFRJ (Rio de Janeiro, RJ. Br).

ligia@ipub.ufrj.br

This is an open-access article, which permits unrestricted use, distribution,

\section{(cC) BY-NC} and reproduction in any medium for non-commercial purposes provided the original authors and sources are credited. 